\title{
Understanding the Barriers to Sustainable Solid Waste Management in Society 5.0 Perspective Under Uncertainties: A Hybrid Method Approach
}

\section{Tat-Dat Bui}

Asia University

Ming-Lang Tseng ( $\nabla$ tsengminglang@gmail.com )

Asia University https://orcid.org/0000-0002-2702-3590

\section{Research Article}

Keywords: sustainable solid waste management, society 5.0 perspective, fuzzy Delphi method, fuzzy decision-making trial and evaluation laboratory, Choquet integral

Posted Date: May 18th, 2021

DOl: https://doi.org/10.21203/rs.3.rs-441044/v1

License: (c) (1) This work is licensed under a Creative Commons Attribution 4.0 International License.

Read Full License 
1 Understanding the barriers to sustainable solid waste management in society 5.0 perspective under uncertainties: a hybrid method approach

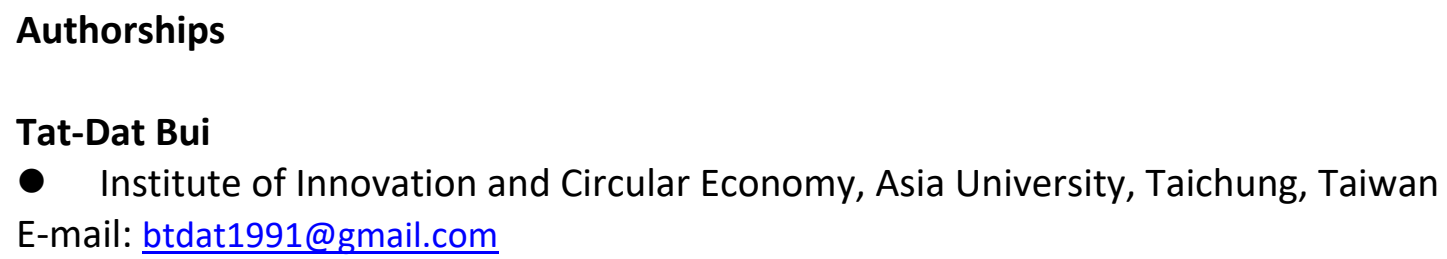

Ming-Lang Tseng

- Institute of Innovation and Circular Economy, Asia University, Taichung, Taiwan

- Department of Medical Research, China Medical University Hospital, China Medical University, Taichung, Taiwan

- Faculty of Economic and Management, University Kebangsaan Malaysia, Malaysia

E-mail: tsengminglang@gmail.com; tsengminglang@asia.edu.tw 
Understanding the barriers to sustainable solid waste management in society 5.0 perspective under uncertainties: a hybrid method approach

\section{Abstract}

This study contributes to identifying a valid and reliable set of barriers to sustainable solid waste management framework rooted in society 5.0 perspectives in Taiwan. In nature, the hierarchical structure is with the causal interrelationships under uncertainties. The perspective empowers the creation of a new biosphere based on technological progress, but in the sustainable solid waste management field, it is difficult to encounter and shape the systematized processes due to barriers and challenges. To address this shortcoming, this study evaluates the technical challenges faced in the field of sustainable solid waste management toward society 5.0. The valid attributes are usually described the qualitative information. The fuzzy Delphi method is applied to acquire the valid and reliable attributes. Fuzzy decision-making trial and evaluation laboratory experiment is to visualize the causal interrelationships among the attributes. Choquet integral with respect to the nonadditive attributes over the valid set provides an overall perspective function. The results establish an understanding of sustainable solid waste management barriers in the perspectives under uncertainties. Community uncertainty, policy and regulation problems, city architecture, and technology interaction are the factors that influence sustainable performance. In practices, (1) diverse disciplines and sectors in local, national, and global communities, (2) a lack of mobility and reliability, (3) mass production and mass consumption, (4) an insufficient level of artificial intelligence application, and (5) failures related to data management and security hinder the improvement of sustainable solid waste management toward society 5.0.

Keywords: sustainable solid waste management; society 5.0 perspective; fuzzy Delphi method; fuzzy decision-making trial and evaluation laboratory; Choquet integral 
Understanding the barriers to sustainable solid waste management in society 5.0 perspective under uncertainties: a hybrid method approach

\section{Introduction}

Society 5.0 (s5.0) regards to a supersmart society that addresses diverse social challenges by integrating the industry 4.0 (e.g., the Internet-of-Things, robotics, artificial intelligence (Al), big data, and the sharing economy) into the contexts of production, consumption, and social life (Mohanty \& Kumar, 2021). This concept, along with smart technologies, offers various opportunities to attain the aforementioned goals and introduce changes that support sustainability (De Pascale et al., 2020). Within s5.0 perspective argues that sustainable development goals empower a new biosphere in which human beings lead wealthy and gratifying lives in harmony with social, economic, and technological progress that causes no harm to nature (UN, 2020). In this context, sustainable solid waste management (SSWM), as an integral part of human life that has a strong influence on production and consumption and long-term effects on the environment and human life, has become particularly important when reimagining society (Dubey et al., 2020). This study argues that through SSWM, S5.0 may create new value and a safe environment that make people's lives more consistent with sustainability.

In Taiwan, the environmental challenges facing human society have become increasingly concentrated due to rising living standards (Sung et al., 2020). Taiwan has a high population density that tremendously increases its solid waste generation. In the face of these changes, the government began implementing various solid waste management (SSWM) practices; indeed, it has made significant achievements, as the country's waste management network properly captured and managed $99.98 \%$ of waste in 2020, and the recovery rates reached $53.5 \%$ during that same year (Taiwan Environmental Protection Administration, 2020). Nevertheless, Taiwan's waste treatment infrastructure is continuously strained despite the efficient operation of its waste minimization and resource recovery programs (Sung et al., 2020). Nguyen et al. (2020) noted that various economic and social challenges are unobservably linked to each other, causing multicollinearity problems related to Taiwan's SSWM. Yeh (2020) proposed that structural changes in the community behavior of an economic system and solid waste disposal routines influence SSWM execution. Dissociations between economic growth, environmental pressures, and societal sustainability greatly impedes SSWM technology, which is then pressed to its limits, placing unexpected burdens on society. Society then becomes anxious about the massive amount of accumulated waste material, which inflicts disproportionate pressure on ecosystems (Takana, 2014; DeWit et al., 2020). Therefore, more in-depth study is necessary to improve waste processes and move towards sustainability, as well as to create a society without the risk of resource exhaustion, where cities' bionetworks are conserved deprived of being vulnerable. To pursue sustainability and identify SSWM opportunities, shifting in the proper direction in terms of long-term environmental planning is vital, and s5.0 perspective represents a movement in this direction.

However, making any tangible achievements is difficult due to the current technical and economic conditions, and municipalities' lack of related capabilities; furthermore, individuals' uncertainty and lack of knowledge about adopted technologies also need to be addressed to fully benefit from implemented sustainable societal, environmental, and economic measures (the triple bottom line; TBL) (Tanaka, 2014; Keogh et al., 2020). For examples, Gutberlet et al. (2017) 
indicated that unsustained waste disposal poses severe health risks, as it spreads infectious diseases and contaminates neighborhoods. Dubey et al. (2020) stated that the main problem associated with a fast-growing population is the generation of biodegradable and nonbiodegradable waste that impacts the environment. Although these problems have been known for some time, local authorities have not yet been ready to deal with them, and the application of advanced operational technologies, such smart tools for big data management, and the implementation of information technology systems, is still in an early stage (Foresti et al., 2020). Advanced technology designed to support a healthy environment and society is still limited in terms of understanding the contexts of SSWM and S5.0 perspective; however, achieving this is important, since the need to create an environmentally friendly society with no risk of resource limitations and environmental difficulties is urgent due to unmanaged waste. The difficulties faced in forming systematized processes must be addressed with smart technological innovation that effectively responds to environmental changes, and integrating smart technological innovation into new mechanisms involves many barriers and challenges that hinder waste management practices (Ikhlayel, 2018, Bui et al., 2020a). Achieving SSWM in those perspectives by overcoming these barriers would empower not only local areas but also whole countries to increase their economic development while solving key social problems (Mohanty \& Kumar, 2021). Highlight these barriers is an important step to improve waste management outcomes and executing substitute societal resolutions.

Regarding the literature, Fukuda (2020) emphasized that S5.0 should consider the speed of technology-driven transformation and the unmatched increase in data collection while also considering society itself. Mavrodieva \& Shaw (2020) argued that S5.0 exploits technological innovation to achieve secure and sustainable economic and societal development. Regarding SSWM, Aid et al. (2017) claimed that the interaction between information-related barriers and technical barriers can be identified through the potential of social incorporation and synergic collaborations. Bui et al. (2020a) identified a set of barriers related to SSWM practice and revealed that social acceptability, financial and economic problems, and technical integration are factors that drive SSWM. Although previous studies have discussed and emphasized the essential nature of technical perspectives, certain gaps related to aligning the technical barriers and the nontechnical characteristics of sustainable perspectives to improve SSWM activities have not yet been filled. This study intends to identify barriers related to the TBL and technical challenges to enable SSWM systems to be rooted in S5.0 perspective. This study's objectives of are as follows:

\section{To present a valid and reliable SSWM barrier set rooted in S5.0 perspective;}

To examine the causal interrelationships within the SSWM hierarchical structure under uncertainties;

To identify the critical barriers impeding Taiwan's SSWM practices toward s5.0.

Rapid elaboration, cumulative discernment, and diverse social, political, environmental and economic challenges result in the different technical and nontechnical barriers, making SSWM a complex and uncertain topic (Bui et al., 2020b; Fukuda, 2020). Given the massive number of dimensions and decision-making issues related to sustainability problems, the use of a multiplecriteria decision-making process is suitable. This study adopts a hybrid method that integrates the fuzzy Delphi method, a fuzzy decision-making trial and evaluation laboratory (DEMATEL) and the Choquet integral to develop valid hierarchical measures and identify a causal structure 
among the examined barriers. The Delphi method and experts' judgment are used to validate the structural barriers derived from the literature. The fuzzy DEMATEL is used to explore the causal interrelationships among various SSWM attributes formed by human perceptions (Tseng et al., 2018). However, measuring qualitative perceptions and judgments is difficult. Linguistic vagueness leads to differences in interpretations that reflect various meanings (Bui et al., 2020a). The use of experts' experience, knowledge, and industrial familiarity might cause biased judgments that affect the study's results (Tsai et al., 2020a). Thus, a nonadditive Choquet integral is used to eradicate experts' subjective exertions and evaluate the hierarchical perspectives (Tseng, 2009; Tseng et al., 2015). Since there is a lack of tools designed to evaluate interactions among exhaustive and independent attributes, this method provides a better approach to effectively addressing uncertainty.

This study contributes to both theory and practice: (1) a valid and reliable SSWM barriers set toward S5.0 is presented to extend the understanding of both SSWM in S5.0 perspective in the literature; (2) the SSWM-related causal interrelationships within the proposed hierarchical structure are examined, and the dependencies among the proposed barriers are shown; and (3) critical barriers for the practical improvement and enhancement of SSWM performance in the context of achieving S5.0 are identified.

The remainder of this study is organized in 5 sections. The second section provides a discussion regarding the S5.0 perspective and SSWM-related literature, the proposed method and the barriers selected for measurement. The case background and employed methodology are addressed in the third section. The next two sections reveal the results and provide implications for theory and practice. The final section contains the conclusion, contributions, limitations and future study recommendations of this study.

\section{Literature review}

201 This section goes into a review of the S5.0 perspective and the SSWM-related literature, the 202 proposed method and the barriers selected for measurement.

\subsection{Society 5.0}

S5.0 was first defined as a novel social ecology network that involved a number of strategic deviations going beyond constant digital technological dissemination into all human spheres of existence to launch a high-tech aided, supersmart society (Bryndin, 2018). Fukuyama (2018) and Fukuda (2020) described S5.0 as an information-based society aiming for a wealthy humancentered culture built through cumulative modernization and the digitization of industrial and societal infrastructure. Mohanty \& Kumar (2021) described it as an innovative society centered on individuals and communities, where newly created value eliminates age-, gender-, region-, and language-related differences and finally enables product/service deliveries to be made-toorder according to diverse discrete and latent requirements. In this manner, S5.0 makes it possible to encourage economic growth and discovery resolutions to social difficulties through thinking about advanced designs and systemics that enable a futuristic sustainable society in harmony with the natural environment. This evolution is argued to have substantial impacts on how society approaches and designs the future (Gladden, 2019; Mavrodieva \& Shaw, 2020). However, whether the S5.0 paradigm as a whole is practical remains unclear despite various

218 explorations of its benefits (Keogh et al., 2020). Since the literature on S5.0 perspective is in an 
emerging development stage, it is important to create a sustainable ecosystem consistent with the existing rapid technological and digital progression toward S5.0.

This study draws upon SSWM viewpoints to conduct an empirical analysis toward S5.0 perspective. The connections are needed as one of the steps to providing a dynamic, comfortable, and sustainable human-centric ecosphere (Ferreira \& Serpa, 2018). Undeniably, the adoption of advanced technology designed to support a healthful ecology and society are not able to separate from understanding the S5.0 and SSWM context; however, an ostensible inconsistency comes alongside the attempts to form a more human-centric society in that human beings exist in conjunction with a range of progressively independent social robots and Al forms, which leads to numerous challenges related to the development of society (Gladden, 2019). Thus, there must be a cognizant effort to strike a balance between intermittent modernization and resolution and the expansion of high speculative and recompense technologies; this is a noteworthy prospect, but some efforts on developing and implementing S5.0 technologies may end in expensive malfunction. This has led to the need to identify insufficient and inaccurate barriers since there is a level of uncertainty regarding the socioeconomic and dynamic nature of SSWM planning in the context of S5.0.

\section{Sustainable solid waste management}

SSWM is an important part of cities, and it incorporates a management process that involves multiple TBL attributes, policy and legislation, and technical implementations related to fulfilling a societal demand by providing proper waste management resolution for neighborhoods (Bui et al., 2020a). Indeed, SSWM is essential at all stages of city development, with designing, planning, organizing, and constructing, to ensure the sustainability of future development goals. Therefore, it is necessary to emphasize the research and development of advanced technology for SSWM (Bui et al., 2020a, b). Standardized technology design, assortment, planning and operation of waste management facilities and waste assortment and transport infrastructure is required to guarantee appealing and operative practice.

As the implementation of smart technology increases, it is argued that S5.0 will provide opportunities for SSWM to unlock the full potential of new operational hardware instruments, data and software tools are integrated into waste management models to develop SSWM solutions (Anagnostopoulos et al., 2017). Innovative smart management tools, such as devices that have expressive computational capabilities or that provide intelligent services, are embedded into such environments to collect and manage ambient information in addition to information related to SSWM activities. Islam \& Jashimuddin. (2017) assessed the cost-benefit features and energy reliability of waste-to-energy recovery utilization techniques in a capital city. Dubey et al. (2020) examined a waste management collection and decomposition system towards the Internet-of-Things and machine learning in a smart society. Onoda (2020) argued for the use of S5.0 tactics to waste management and tried to make the case for an evolution in smart cities. Hence, selecting suitable environmental technology and integrating S5.0 perspective by encouraging smart waste management may help municipalities achieve sustainability.

However, previous studies have also highlighted the absent of specialized technology, information and knowledge distribution in the field of SSWM (Yukalang et al., 2017). Sakr et al. (2011) recorded that difficulties increase when information technology application is missing to address the uncertainties or vagueness related to waste management. SSWM practitioners must overwhelm such blockades to progress their performance and make an consciousness of 
management. Yukalang et al. (2017) noted that the SSWM information provision is inadequate and require more adjudgment for easier assessments. There is an urgent need for a cohesive, strategic conveyance of future trends related to SSWM that considers the barriers that drive unsustainability and treats them as an important set of potential challenges (Aid et al., 2017, Bui et al., 2020b). Identifying SSWM barriers in the context of S5.0 is an essential step towards waste management improvement and the execution of appropriate solutions.

\section{Proposed method}

In the literature, Mavrodieva \& Shaw (2020) analyzed information in official practical implementation documents to discuss climate change and disaster issues in the context of S5.0. Foresti et al. (2020) used building information modeling to develop an instinctive self-restoring procedure and designed smart conventions for factories, Industry 5.0, and S5.0 to efficiently provide feedback for unrefined Al data and design schedules. However, studies considering the complexity and assessing the uncertainty of SSWM in the context of S5.0 are still lacking, causing difficulties in establishing appropriate operational networks (Bui et al., 2020b). Even though the above studies have emphasized these issues, a classification designed for multiple-attribute modeling under uncertainties has not yet been fully addressed. Addressing the extensive, complex challenges facing SSWM organizations and society requires appropriate tools.

Multiple criteria decision-making tools are respected for complementing sustainability perspectives, as there are conflicting relationships inside complex systems (Gonzalez et al., 2015; Keogh et al., 2020). This study uses a hybrid method assimilating the FDM, the fuzzy DEMATEL method and the Choquet integral to develop valid hierarchical measures and a causal structure of the SSWM barriers in the context of S5.0. On the one hand, the FDM is applied to validate structural barriers derived from the literature based on experts' evaluations. Tseng et al. (2015) implied that the FDM can be used to integrate the interactive and systematic estimations of experts who make judgments regarding planning, identification and prioritization strategies and framework development. Bui et al. (2020a) claimed that this method is useful for identifying, selecting and validating attributes within a hierarchical framework to enable extra examination. The fuzzy DEMATEL method is utilized to determine the causal interrelationships among SSWM attributes by transforming linguistic perceptions into quantitative data, which are then converted to crisp values (Tseng et al., 2018). Tsai et al. (2020a) utilized the fuzzy DEMATEL method to scrutinize the interactions between various attributes and develop a causal structure of certain attributes. Bui et al. (2020b) developed a set of SSWM attributes under uncertainties and identified a structure of causal interrelationships among them using this method.

However, linguistic vagueness leads to differing interpretations that reflect various meanings; experts' knowledge, experience, and industrial familiarity can involve subjective judgments that may significantly affect the results of a study (Bui et al., 2020b; Tsai et al., 2020a). A nonadditive Choquet integral is used to remove the experts' subjective evaluation and establish hierarchical consistency (Tseng, 2009; Tseng et al., 2015). Tseng et al. (2009) adopted a Choquet integral to identify optimal suppliers in independent supply chain management strategies. Tseng et al. (2015) used a Choquet integral approach to systematically evaluate a diversified set of independent criteria related to service innovation. Since attribute independence assumptions are not suited to additive multilevel structures, the method confirms the interdependency of the data and affirms the data's prioritization for optimal performance. 
Rapid development, cumulative discernment, and diverse social, political, environmental and economic challenges result in the different technical and nontechnical difficulties, making SSWM complex and uncertain (Bui et al., 2020a; Fukuda, 2020). Given the massive number of dimensions and issues related to decision-making problems involving sustainability, a hierarchical approach is suitable. This study evaluates TBL perspectives on sustainability in addition to the technical challenges faced in the context of SSWM within S5.0.

S5.0 struggles to transition ahead of industry and shape a supersmart society where new knowledge, technology, and values are constantly generated to provide improved living standards and economic growth (Fukuda, 2020). As the foundation of cities and society development, waste management requires technologically innovative approaches to extrapolative and adaptive social practices (P1). In fact, new technologies have an important influence on citizens' ability to make decisions on social and environmental development and to maximize social wellbeing and justice without harming the ecosystem (Roblek et al., 2020). However, the implications of S5.0 potentially include extraordinarily high-speed outcomes related to the integration of innovative technology into social life, and such communities would thus face a complex flow of tangible good and bad impacts without notice (Ferreira \& Serpa, 2018). Therefore, a S5.0 that incorporates SSWM needs to account for community uncertainty (A1) and promote publicly attainable goals during the development process (Mavrodieva \& Shaw, 2020). Communities needs to address these difficulties since resource depletion causes security and social threats. Furthermore, society also faces ethical issues, as diverse nations, regions and communities can have unalike principles and ideas regarding how the information should be handled (Keogh et al., 2020). This introduces vulnerability regarding citizens' information, as clear mechanisms for incorporating their right of speech are missing, and biases are created in the decision-making process. Improper technology adoption, a lack of social facilities, a low awareness of these issues, and behavioral changes must be addressed to implement and sustain best practices throughout an entire SSWM system (Casazza and Gioppo, 2020; Roblek et al., 2020).

Policy and regulation problems (A2) still exist, as a lack of regulation, direction, policy norms, standardization, transparency and connectivity are critical factors that cause city development to fail, particularly in the context of SSWM practices (Sharma et al., 2020). The government, together with the community, must examine its institutional reorganization capability and the standardization of its policies and rules as part of its strategic development towards S5.0 implementation, ensuring that social benefits are distributed evenly and responsibly (Tanaka, 2014). Nevertheless, these new policies suggest the inclusion of novel activities, and certain generations, such as elderly individuals, who will tolerate a brunt of adapting from these hasty changes, as they are stuck in the trial-and-error progression. A synchronization of the regulatory norms and political directions related to SSWM technological innovations is urgently needed, as there is a danger that waste management reliability and mobility are still lacking, remaining mostly optional rather than legally binding to minimum standards.

Mass production and consumption have resulted in natural resource depletion, toxic substance emissions, incinerator and dioxin pollution, and other kinds of environmental degradation (P2). Human activities and economic development severely affect city ecosystems 
problems related to limited resource availability and solid waste conservation capacity, leading to the risk that existing waste management networks negatively affect the society existence. For example, the disposal of different solid wastes, illegal dumping and improper waste disposal are thought to be management issues that have long-term environmental influences (Ikhlayel, 2018). Augmented waste generation causes additional environmental problems that challenge the implementation of SSWM due to slow local sustainable development (Tsai et al., 2020b).

A society is in the 5.0 stage of its development when it is smart in terms of waste management, energy savings, and environmental conservation (Dubey et al., 2020). Still, there is no focus on infrastructure and energy consumption (A4) solutions designed to waste reduction, reuse and recycling, and energy recovery processes, resulting in big amount of disposed waste and environmental pollution (Bui et al., 2020a). Thus, selecting SSWM solutions based on each locality's strengths and resources and environmentally friendly technologies suited to the nature of each location's waste are required (Bui et al., 2020b). Additionally, cities are moving towards a sustainable society based on technology that helps citizens engage in their chosen activities in flexible ways and guides them to engage in energy-efficient behavior (Mohanty \& Kumar, 2021). Public infrastructure also helps limit wasteful energy use if it dynamically reflects usage levels. Yet, deintensifying urban areas still need a distributed system that provides high levels of independence and mobility as well as an effective integration of land use and vacant land management (Murayama, 2020).

S5.0 is considered to convey citizens economic assistance (P3) by delivering appropriate amounts of necessary products/services to citizens in need in a timely manner by way of emerging technologies (Gladden, 2019). An effective SSWM system also utilizes economic and technological advantages to promote environmental harmony and social enrollment (Bui et al., 2020b; Keogh et al., 2020). A clear economic development design is urgently needed to address various costs and expenditures (A5), including those related to restructures due to information changes and adaptive risk as well as response procedures within SSWM programs (DeWit et al., 2020; Mavrodieva \& Shaw, 2020;). Nevertheless, society struggles to implement these new plans due to technical, financial, and economic constraints (Sharma et al., 2020). Improved SSWM practices such as those related to waste handling and waste fraction collection, with a view to quantitative production regarding packaging and qualitative waste impediment, require extra time and are often costly, leading to reduced acceptance and resistance.

City architecture (A6) is a vital barrier because it provides enhancement or unite effective waste-processing technologies through accommodation, restoration, or backdrop designs (Bui et al., 2020a). Due to the numerous socioeconomic challenges and constantly increasing risk of frequent and strong environmental impacts facing society, there is a need to implement a novel inclusive strategy, namely S5.0 architecture, which utilizes various technologically innovative solutions to provide a secure environment for its citizens and solutions for some important issues, particularly waste management (Mavrodieva \& Shaw, 2020). It is suggested that communities develop ecological architecture designs that can guarantee resource availability over the long run and that use software analytics to implement the proposed SSWM approaches (Anagnostopoulos et al., 2017). Unsynchronized local architecture and design operations methodologies might result in unsustainable waste management and corrupt sanctions. A sustainable construction 


\section{Method}

4283.1 . 2020).

traditional design is able to increase economic efficiency with marginal processing and transportation burdens for waste management systems.

It is argued that technical integration drives SSWM, and technical difficulties (P3) represent an important factor that causes poor SSWM performance (Tsai et al, 2020a; Bui et al., 2020a). When choosing suitable technology principles, it is vital to have information on the local SSWM status since S5.0 is designed to create new value by facilitating cooperation and collaboration among different technology systems, and developing necessary human resources (Ferreira \& Serpa, 2018). Specifically, S5.0 provide SSWM opportunities to expose the greatest possibility of innovative technologies: a concept of waste management designed to employ smart technology interaction (A7) as a basis for classifying waste management structures that integrate cyberphysical infrastructure, the Internet-of-Things, and software analytics (Anagnostopoulos et al., 2017). Emerging technology is expected to enhance smart applications, transnational normalization, big data technologies, and so on, encouraging societal development (Tabaa et al.,

S5.0 improves personal and professional ways of life and community lifestyles. Society categorizes and analyzes the probability that robotics, Al, and augmented humans will be deeply integrated into nature through futuristic technologies (Ferreira and Serpa, 2018; Gladden, 2019). However, although advanced technology applications can syndicate and scrutinize progressively complex unrelated data and vast amounts of information, as they obligatory an inordinate time consuming and human resources (A8) to do so (Mavrodieva \& Shaw, 2020). However, there is a lack of knowledge and skill regarding the operational integration needed to ensure that unconventionalities regarding SSWM are no longer affecting the development of society; thus, empirical customization is required to identify inefficiencies or changes that should be made, especially in human-machine interactions (Foresti et al., 2020). Overall, there are large-scale societal 5.0 changes and SSWM barriers related to the integration of technical and social factors into human society, and these bring considerable new ethical, practical, and security challenges.

The proposed hierarchical structure including 4 perspectives, 8 aspects, and 45 barriers is shown in Table 1

The case background and method using FDM, fuzzy DEMATEL, and a Choquet integral are precisely addressed in this section.

\section{(INSERT Table 1 here- Proposed hierarchical structure)}

\section{Case background}

The SSWM system in Taiwan embodies a case study that is suitable for recognizing the socioeconomic benefits of SSWM implementation, particularly in the case of emerging countries. This is because Taiwan not only succeeds in terms of solid reduction and resource recovery programs but also has experienced rapid industrialization and urbanization during the last few decades. An integrated system guarantees that SSWM production and consumption is promoted via public policies that invest in the expansion of environmentally friendly industries and that improve society's awareness of such issues with the aim of creating a recycling economy (Nguyen et al., 2020; Yeh et al., 2020). As an outcome, in 2020, 97.42\% of the waste in Taiwan was 
incinerated, and the resource recovery rate reached $55.5 \%$; indeed, only $2.58 \%$ of the country's waste was landfilled (Taiwan Environmental Protection Administration, 2020).

For the last decade, Taiwan's SSWM progress regarding the reduction of waste has been appraised. Incineration has substituted landfills as the primary waste disposal method because landfills are not suitable for Taiwan's typhoon-prone weather, as waste easily pollutes the natural environment and destroys entire ecosystems. The government has built 26 large incinerators, but they have been met with a wave of environmental opposition related to environmental protection and community health (Sung et al., 2020). In addition, many of them face either a need for maintenance or an end-of-life period. SSWM technologies are reaching their respective frontiers; this challenge is accompanied by frequent natural disasters, such as earthquakes and typhoons, which have boosted the unexpected encumbers on society. Choosing the proper trend in relation to the sustainability of society is vital as a long-term environmental strategy, and it is urgent that long-term SSWM opportunities are taken advantage of. Taiwan, with its ambition to become a zero-waste society and the political pressure that it faces on environmental cleanliness, has placed significant pressure on society (Taiwan Environmental Protection Administration, 2021). S5.0 and high-tech facilities represent an SSWM improvement in the context of a complex socioeconomic system. This study aims to build a SSWM paradigm with new added value and advanced strategic mechanisms.

This study evaluates experts' perceptions on the major SSWM barriers by applying the FDM, the fuzzy DEMATEL method, and a Choquet integral. The theoretical appraisal and proposed SSWM barriers are derived from the literature and expert counsellors. Face-to-face interviews are employed to appraise the knowledge and reliability of participating expert. A committee with 32 experts is utilized, including 16 experts from academia, 5 experts from government agencies, and 8 experts from practical fields with experience working and studying in the SSWM field.

Fuzzy Delphi method

The integration of fuzzy set theory and the traditional Delphi method is proposed to handle the linguistic preferences of the experts (Ishikawa et al., 1993). The linguistic terms are interpreted into triangular fuzzy numbers (TFNs), as shown in Table 2. Expert $x$ is then required to assess the significance of attribute $y$ as $j=\left(a_{x y} ; b_{x y} ; c_{x y}\right) ; x=1,2,3, \ldots, n$; and $y=$ $1,2,3, \ldots, m$. Thus, $j_{y}$ is the weight of attribute $y$ and $j_{y}=\left(a_{y} ; b_{y} ; c_{y}\right)$, where $a_{y}=\min \left(a_{x y}\right)$, $b_{y}=\left(\prod_{1}^{n} b_{x y}\right)^{1 / n}$, and $c_{y}=\max \left(c_{x y}\right)$.

The $D_{b}$, convex combination value, is generated using an $\rho$ cut as follows:

$$
u_{y}=c_{y}-\rho\left(c_{y}-b_{y}\right), l_{y}=a_{y}-\rho\left(b_{y}-b x_{y}\right), y=1,2,3, \ldots, m
$$

The $\rho$ value is adjusted between 0 and 1 based on the negativity or positivity of the experts' judgments. Generally, the value $\rho=0.5$ denotes indifference. Formerly, the precise $D_{b}$ is generated as follows:

$$
D_{y}=\int\left(u_{y}, l_{y}\right)=\alpha\left[u_{y}+(1-\alpha) l_{y}\right]
$$

where $\alpha$ represents equilibrium among the fundamental judgments of the expert group.

Then, the threshold $\gamma=\sum_{a=1}^{n}\left(D_{b} / n\right)$ is established to identify the valid attributes. If $D_{b} \geq \gamma$, attribute $b$ is validated. Otherwise, it is obliged to be excluded.

(INSERT Table 2 here- FDM linguistic terms' transformation table) 
4803.3.

Fuzzy DEMATEL

503

504

505

506

507

508

509

510

511

512

513

514

515

516

14

The fuzzy DEMATEL method is used to simplify the examined complex interrelationship problems by interpreting the experts' linguistic judgments into fuzzy values. Using the defuzzification technique, the fuzzy maximum and minimum numbers are employed to convert the TFNs into crisp values by calculating the right and values left (Bui et al., 2020b). Next, the fuzzy membership function weight $\tilde{\mathrm{r}}_{\mathrm{ij}}^{\mathrm{k}}=\left(\widetilde{\mathrm{r}}_{1 \mathrm{ij}}^{\mathrm{k}}, \tilde{\mathrm{r}}_{2 \mathrm{ij}}^{\mathrm{k}}, \widetilde{\mathrm{r}}_{3 \mathrm{ij}}^{\mathrm{k}}\right)$ is used to abridge the weighted values. The total direct relation matrix is rearranged according to the crisp values. A visual causal diagram is mapped using the DEMATEL method to present the analytical results and describe the interrelationships among the attributes.

Presuming the existence of the attribute set $E=\left\{\mathrm{e}_{1}, \mathrm{e}_{2}, \mathrm{e}_{3}, \cdots, \mathrm{e}_{\mathrm{n}}\right\}$, a pairwise comparison is adopted to clarify the precise relationships between each pair of attributes. The five linguistic preferences are ranked from VL (very low influence) to VHI (very high influence), and these are exploited to construct the attributes' fuzzy direct relation matrix, as shown in Table 3 . If $\mathrm{k}$ members are included in the decision committee, the $\mathrm{i}^{\text {th }}$ attribute influencing the $\mathrm{j}^{\text {th }}$ attribute assessed by the $\mathrm{k}^{\mathrm{th}}$ expert is denoted as the fuzzy weight $\tilde{\mathrm{e}}_{\mathrm{ij}}^{\mathrm{k}}$.

\section{(INSERT Table 3 here- Fuzzy DEMATEL linguistic terms' transformation table)}

The corresponding fuzzy numbers are then transformed as follows:

$$
\mathrm{E}=\left(\mathrm{e} \tilde{\mathrm{r}}_{1 \mathrm{ij}}^{\mathrm{k}}, \mathrm{e} \tilde{\mathrm{r}}_{2 \mathrm{ij}}^{\mathrm{k}}, \mathrm{e} \tilde{\mathrm{r}}_{3 \mathrm{ij}}^{\mathrm{k}}\right)=\left[\frac{\left(\mathrm{r}_{1 \mathrm{ij}}^{\mathrm{k}}-\operatorname{minr}_{1 \mathrm{ij}}^{\mathrm{k}}\right)}{\Delta}, \frac{\left(\mathrm{r}_{2 \mathrm{ij}}^{\mathrm{k}}-\operatorname{minr}_{2 \mathrm{ij}}^{\mathrm{k}}\right)}{\Delta}, \frac{\left(\mathrm{r}_{3 \mathrm{ij}}^{\mathrm{k}}-\operatorname{minr}_{3 \mathrm{ij}}^{\mathrm{k}}\right)}{\Delta}\right]
$$

$$
\text { where } \Delta=\operatorname{maxr}_{3 \mathrm{ij}}^{\mathrm{k}}-\operatorname{minr}_{1 \mathrm{ij}}^{\mathrm{k}}
$$

The left (lv) and right (rv) values are converted into normalized values, as shown in equation 2 , and these are then used to compute the total normalized crisp values, as shown in equation 3 :

$$
\left(l v_{i j}^{n}, r v_{i j}^{n}\right)=\left[\frac{\left(e_{2 i j}^{k}\right.}{\left(1+e r_{2 i j}^{k}-f r_{1 i j}^{k}\right)}, \frac{e_{3 i j}^{k}}{\left(1+e r_{3 i j}^{k}-e r_{2 i j}^{k}\right)}\right]
$$

$$
c v_{\mathrm{ij}}^{\mathrm{k}}=\frac{\left[\mathrm{lv}_{\mathrm{ij}}^{\mathrm{k}}\left(1-\mathrm{l} v_{\mathrm{ij}}^{\mathrm{k}}\right)+\left(\mathrm{rv} v_{\mathrm{ij}}^{\mathrm{k}}\right)^{2}\right]}{\left(1-\mathrm{lv} v_{\mathrm{ij}}^{\mathrm{k}}+\mathrm{r} v_{\mathrm{ij}}^{\mathrm{k}}\right)}
$$

A synthetic value is obtained to calculate the individual judgment of each expert as follows:

$\tilde{\mathrm{r}}_{\mathrm{ij}}^{\mathrm{k}}=\frac{\left(\mathrm{cv}_{\mathrm{ij}}^{1}+\mathrm{cv}_{\mathrm{ij}}^{2}+\mathrm{cv} \mathrm{ij}^{3}+\cdots+c v_{\mathrm{ij}}^{3}\right)}{\mathrm{k}}$

By forming pairwise comparisons, the (DR), an $(n \times n)$ initial direct relation matrix, is acquired, in which $\tilde{r}_{i j}^{k}$ represents the values of attribute i imitates attribute $j$, and this matrix is reformed as $\mathrm{IM}=\left[\tilde{\mathrm{r}}_{\mathrm{ij}}^{\mathrm{k}}\right]_{\mathrm{n} \times \mathrm{n}}$.

Then, the (DM), normalized direct relation matrix, is calculated as follows:

$\mathrm{DM}=\tau \otimes \mathrm{DR}$

where $\tau=\frac{1}{\max _{1 \leq i \leq k} \sum_{j=1}^{k} \tilde{r}_{i j}^{k}}$

The total interrelationship matrix (TM) is computed as:

$\mathrm{TM}=\mathrm{DM}(\mathrm{I}-\mathrm{DM})^{-1}$ 
where TM signifies $\left[\operatorname{tm}_{\mathrm{ij}}\right]_{\mathrm{n} \times \mathrm{n}} \mathrm{i}, \mathrm{j}=1,2, \cdots \mathrm{n}$

Finally, the driving power $(\gamma)$ and the dependent power $(\delta)$ are calculated as the sum of the values in the rows and columns of the total relation matrix as follows:

$$
\begin{aligned}
& \gamma=\left[\sum_{\mathrm{i}-1}^{\mathrm{n}} \mathrm{tm}_{\mathrm{ij}}\right]_{\mathrm{n} \times \mathrm{n}}=\left[\mathrm{tm}_{\mathrm{i}}\right]_{\mathrm{n} \times 1} \\
& \delta=\left[\sum_{\mathrm{j}-1}^{\mathrm{n}} \mathrm{tm}_{\mathrm{ij}}\right]_{\mathrm{n} \times \mathrm{n}}=\left[\mathrm{tm}_{\mathrm{j}}\right]_{1 \times \mathrm{n}}
\end{aligned}
$$

A causal interrelationship diagram is mapped to identify attributes using $(\gamma+\delta)$ and $(\gamma-\delta)$ iteratively as horizontal and vertical axes. In this process, $(\gamma+\delta)$ indicates the importance of the attributes; the higher the value of $(\gamma+\delta)$ is for a given attribute, the more important the function of that attribute is. Then, $(\gamma-\delta)$ is used to assembly the attributes to cause-and-effect groups by defining whether $(\gamma-\delta)$ is positive or negative. If $(\gamma-\delta)$ is positive for a given attribute, that attribute is placed into the causing group; otherwise, it belongs to the affected group.

\section{Choquet integral}

An unweighted supermatrix is obtained to handle with the transaction between the criteria, aspects and perspectives (Tseng et al, 2009). Adjusting weights for each expert evaluation must be added to the weighted supermatrix since it is incapable of reproducing the stochastic determinant. The interdependent convergence is then generated to precisely mold the relative weights of the attributes as:

$$
H^{*}=\lim _{n \rightarrow \infty} H^{n}
$$

A nonadditive fuzzy integral is a numerically based method for patterning gradients and image segmentation. Fuzzy integral adoption can be used in aggregation membership to capture the importance of individual criteria or their combinations (Grabisch ,1996; Tseng et al., 2009). Specifically, monotonic and nonadditive fuzzy integrals are introduced to assess the comparative rank of the measured attributes and model the preference structure; additionally, the $\lambda$-additive axiom is unified to diminish the related data collection difficulties. In the fuzzy measure space $(X, \beta, g)$, let $\lambda \in(-1, \infty)$. If $A \in \beta, B \in \beta, A \cap B=\phi$, the fuzzy measure $g$ is $\lambda$-additive, and can be called the Sugeno measure.

Assuming that $X=\{x 1, x 2, x 3, \ldots, x n\}$ and $P(X)$ is the $X$ 's power set, the functional set $g: P(X) \rightarrow[0,1]$ is a nonadditive fuzzy measurement that has the following properties:

$$
g(\phi)=0
$$

$g(X)=1$;

$$
\text { if } A, B \in P(X) \text { and } A \subset B \text { then } g(A) \leq g(B) \text { (monotonicity); }
$$

In $P(X)$, if $A_{1} \subset A_{2} \subset A_{3} \subset A_{4} \cdots \cdots$ and $U_{i=1}^{\infty} A_{i} \in P(X)$, then $\lim _{i \rightarrow \infty} g\left(A_{i}\right)=g\left(U_{i=1}^{\infty} A_{i}\right)$; and

In $P(X)$, if $A_{1} \supset A_{2} \supset A_{3} \supset A_{4} \cdots \cdots$ and $\cap_{i=1}^{\infty} A_{i} \in P(X)$, then $\lim _{i \rightarrow \infty} g\left(A_{i}\right)=g\left(\cap_{i=1}^{\infty} A_{i}\right)$ (continuity from above).

Furthermore, the $\lambda$-fuzzy measurement also refers as the additional possessions as follows: 


$$
g(A \cup B)=g(A)+g(B)+\lambda g(A) g(B)
$$

where $\lambda>0$ for all $A, B \in P(X)$ and $A \cap B=\phi$. Assuming that $X$ is a determinate set, afterward $U_{i=1}^{n} A_{i}=X$. The $\lambda$-fuzzy measurement $g$ is denoted as:

$$
g(X)=g\left(U_{i=1}^{n} A_{i}\right)=\left\{\begin{array}{c}
\frac{1}{\lambda}\left\{\prod_{i=1}^{n}\left[1+\lambda g\left(A_{i}\right)\right]-1\right\} \\
\sum_{i=1}^{n} g\left(A_{i}\right)
\end{array}\right\} \begin{aligned}
& \text { if } \lambda \neq 0, \\
& \text { if } \lambda=0,
\end{aligned}
$$

where $A_{i} \cap A_{j}=\phi$ for all $i, j=1,2,3, \ldots, n$ and $i \neq j$. If $\lambda \neq 0$, then the $\lambda$-fuzzy measurement $g$ is nonadditive; or else, the $\lambda$-fuzzy measurement $g$ is additive, and there are no interrelations among $A i$ and $A j$ for $i \neq j$. The existence of an interrelation denotes the existence of information synthesis between attributes. $\lambda>0$ infers $g(A \cup B)=g(A)+g(B)$ and that the $\{A, B\}$ set has multiplicative effect; however, $\lambda<0$ implies that the $\{A, B\}$ set has a substitutive effect. In the fuzzy measurement space $(X, \beta, g)$, let $h$ be a measurable occupation of $X$ from $[0,1]$; then, the fuzzy integral definition of $h$ over $A$ can be given to $g$ as:

$$
\int_{A} h(x) d g=\sup _{\alpha \in[0,1]}\left[\alpha \wedge g\left(A \cap F_{\alpha}\right)\right]
$$

where $F \alpha=\{x \mid h(x) \square \alpha\}$ and $A$ is a fuzzy integral domain. the fuzzy integral is signified by $\int h d g$ when $A=X$. Deliberate the fuzzy measurement $g$ of $(X, P(X))$, where $X$ refers to a determinate set. Let $h: X \square[0,1]$ and presume that there is no generality loss, the function $h(x i)$ is monotonically declining with reference to $i$; for example, $h(x 1) \square h(x 2) \square \ldots \square h(x n)$. The attributes in $X$ are renumbered as:

$$
\int h(x) g=\underset{i=1}{n}\left[h\left(x_{i}\right) \wedge g\left(H_{i}\right)\right.
$$

$$
\text { where } H=(x 1, x 2, \ldots \ldots ., x i), i=1,2, \ldots, n \text {. }
$$

Since $h$ is an attribute affecting a set of criteria; $g$ denotes each attribute's comparative rank. The fuzzy integral $h(x)$ uses $g$ to represent an attribute's overall assessment. The fuzzy measurement of the Choquet integral is denoted as:

$$
\text { (c) } \int h d g=h\left(x_{n}\right) g\left(H_{n}\right)+\left[h\left(x_{n-1}\right)-h\left(x_{n}\right)\right] g\left(H_{n-1}\right)+\ldots \ldots . .+\left[h\left(x_{1}\right)-h\left(x_{2}\right)\right] g\left(H_{i}\right)
$$

$$
\text { where } 0 \leq h\left(x_{1}\right) \leq h\left(x_{2}\right) \leq \ldots \ldots \ldots . h\left(x_{n}\right) \leq 1, h\left(x_{0}\right)=0 \text { and } H i=\{x(i), \ldots \ldots, x(n)\} \text {. }
$$

The fuzzy integral described by $\int h d g$ is named the "Choquet integral". The fundamental concept is showed in Figure 1. The fuzzy integral measurement model confirms that there is interdependency among the attributes; therefore, this integral is used in nonlinear cases.

\section{(INSERT Figure 1 here- Choquet integral's basic concept)}




\section{Results}

594 This section reveals the results of the FDM, fuzzy DEMATEL method and Choquet integral. A valid 595 SSWM barrier structure for S5.0 is established. The causal interrelationships between the 596 identified aspects of the critical barriers are identified.

5974.1. Fuzzy Delphi method

$598 \quad$ This study proposed 45 barriers with 8 aspects as the initial attributes. The FDM results are 599 shown in Table 3 with the weights and thresholds used to filter the valid attributes. After the 600 analysis process, the linguistic references are converted into corresponding TFNs, as shown in 601 Table 2. The FDM is used to screen out invalid barriers with the threshold $\gamma=0.363$, as shown in 602 Table 4. After this process, 20 barriers are accepted and 25 barriers are eliminated along with 603 their waste management features (A3) because all these barriers are removed from the initial 604 structure. The valid hierarchical structure is shown in Table 5.

605

606

607

608

609

6104.2.

\section{(INSERT Table 4 here- FDM barriers result)}

\section{(INSERT Table 5 here- Valid hierarchical structure)}

611

612

613

614

615

616

617

618

619

620

621

622

623

624

625

626

627

628

629

630

631

632

633

634

635

636

Fuzzy DEMATEL

The linguistic references from expert regarding the interrelationships of aspects are transformed into TFNs using the linguistic scale shown in Table 3. The TFNs are then normalized into crisp values that are comparable and computable; these can be transformed into exact crisp values using synthetic value notation, as shown in Table 6.

\section{(INSERT Table 6 here - Aspects' script value)}

Then, the crisp values are organized into an interrelationship matrix and aspect groupings to examine their interrelationships with a cause-and-effect diagram. The matrix is rehabilitated into causal interrelationships, as shown in Table 7. A cause-and-effect diagram is drawn based on the $[(\gamma+\delta),(\gamma-\delta)]$, as shown in Figure 2 . The results show that community uncertainty (A1), policy and regulation problems (A2), city architecture (A6), and technology interaction (A7) are allocated into the cause group and have strong influences within the system, while infrastructure and energy consumption (A4), cost and expenditures (A5), and human resources (A8) are assigned to the affected group. In particular, (A2), (A6) and (A7) have strong effects on (A5) and (A8) in the affected group, and (A1) has a strong effect on (A8). Additionally, (A2), (A6) and (A7) have moderate effects on (A4), and (A1) has a moderate effect on (A5). These results reveal an interrelationship network among the attributes.

\section{(INSERT Table 7 here-Aspects' Interrelationship matrix and cause-and-effect interrelationship)}

\section{(INSERT Figure 2 here - Aspect's cause-and-effect diagram)}

Similarly, the cause-and-effect among the criteria are offered in Table 8. This diagram splits the criteria into 2 groups: the cause group includes B3, B6, B10, B14, B15, B32, B34, B36, B37, B38, B39, and B40, whereas the affected group consists of B8, B23, B24, B26, B27, B29, B41, and 
6474.3.

672

673

674

\section{Implications}

676

B44 (as shown in Figure 3). The most important barriers in the cause group are diverse disciplines and sectors in local, national, and global communities (B6), a lack of mobility and reliability (B14), mass production and mass consumption (B34), insufficient Al application (B37), and failures related to data management and security (B40); these are the most concerning barriers that decision makers need to tackle to improve SSWM and achieve S5.0 in practice.

\section{(INSERT Table 8 here - Criteria's cause-and-effect interrelationship)}

\section{(INSERT Figure 3 here - Criteria's causal diagram)}

\section{Choquet integral}

The weighted criteria can be found by integrating the determinant of the converged supermatrix. The integration weights are obtained from the global weights through a normalization process, as shown in Table 9. An interdependent convergent supermatrix is generated with aspect and criteria weight rankings. The results show that city architecture (A6) is ordered as first position in terms of priority, and this is followed by technology interaction (A7), policy and regulation problems (A2), and community uncertainty (A1), which are ranked second, third, and fourth, respectively. Infrastructure and energy consumption (A4), cost and expenditures (A5), and human resources (A8) rank at the structure lowermost. This procedure ensures the aspects consistency through the fuzzy DEMATEL analysis and confirms the proposed hierarchical structure's reliability and validity.

\section{(INSERT Table 9 here- Aspects and criteria global weights suppermatrix)}

A Choquet integral is used to specify the reliability and functionality of the finest perspectives by resolving the $k$-fuzzy measurement. The Choquet integral $(c) \int h d g$ is adopted to generate an aggregated value for each criterion based on its global weight. The overall Choquet integral weight index for the aspects and criteria of each perspective is shown in Table 10. Figure 4 shows the validity of the aspects, criteria, and perspectives, confirming their consistency and showing that they are free from biased judgments and any expert subjective problems introduced by this study's proposed hierarchical structure, as there are no differences between $\lambda=0$ and $\lambda=1$. The social (P1) and technical perspectives (P3) are indicated at the top of the diagram as well as way that these 2 perspectives should be prioritized to improve SSWM performance.

\section{(INSERT Table 10 here- Overall Choquet integral weight index)}

\section{(INSERT Figure 4 here- Choquet integral diagram)}

This section provides this study's theoretical and practical implications. 
6775.1

Theoretical implications

678

679

680

681

682

683

684

685

686

687

688

689

690

691

692

693

694

695

696

697

698

699

700

701

702

703

704

705

706

707

708

709

710

711

712

713

714

715

716

717

718

719

720

This study reveals that community uncertainty, policy and regulation problems, city architecture, and technology interaction have strong influences within SSWM structures in S5.0 perspective.

An innovative human-centered society can generate new value that eliminates gender-, age-, language-, and religion-related inequality among individuals and in communities and keenly empowers product/service delivery to satisfy diverse dormant and detached desires (Mohanty \& Kumar, 2021). S5.0 is complex, as it not only significantly impacts SSWM but also increases people's uncertainty and insecurity. However, changes also bring opportunities; if changes are acknowledged and taken advantage of, a better society can be created. Since S5.0 is primarily based on advanced technologies, a social acceptance of SSWM that predominantly emphasizes technology is needed. Specialists and professionals who are greatly involved in exploring the technology acceptance principal grounds have proposed. Nevertheless, clear guidance is needed on how to use S5.0 SSWM technology in the local community, such as with citizen data or cyberspace architecture, as well as how to facilitate coordination and collaboration to accelerate humans' transition to its use. Understanding humans' acceptance of robots in terms of cultural influence is essential to being more conscientious in this context and experiencing fewer uncertain outcomes.

Policies and regulations are essential to addressing the challenges and opportunities of SSWM and to finding resolutions by examining statistical data on waste generation, amounts and components of solid waste management, waste handling technologies, pecuniary resources, and stakeholder and institution involvement (Tsai et al., 2020a). In S5.0, data from various information sources and social media are exploited, which necessitates an updated system including new data-sharing regulations and transparent connectivity (Mavrodieva and Shaw, 2020). Therefore, addressing both political and regulatory issues regarding SSWM technological innovations is needed to improve the reliability and mobility of waste management and to prevent legally binding risks. In addition, governments and related agencies play an important role in improving this situation by means of formulating new strategies and promoting environmental policies through multistakeholder collaboration. Legal system development and the restructuring of advanced technology and vital cybersecurity policies need to be considered when constructing a new SSWM system. The strategy used to do this should take into account the ethical and legislative issues surrounding Al development, instructions on data sharing, and open up opportunities related to Internet-of-Things security. Hence, changing policies on inclusiveness, the modification of innovative solutions, and the provision of shelter for citizens can lead to a strong legal system and infrequent corruption related to SSWM development towards S5.0.

City architecture enhances and unites effective society-oriented waste-processing technologies (Bui et al., 2020a). This aspect has a considerable influence on how civilization envisions and designs future infrastructure and enables sustainable development (Fukuda, 2020). The results confirmed that SSWM not only reinforces smart technology infrastructure but is also involved in the master plans of inclusive societies by way of integrating factors such as waste management networks and energy efficiency into architectural design. The city architecture of S5.0 helps to improve the resilience and standards of SSWM, especially in locations with vulnerable infrastructure. Yet, SSWM architecture is either designated explicitly or incidentally 
as a part of city systems' designs, still remains unsynchronized with local architecture and operations capacity as a result of unsustainable waste management and persistent corrupt sanctions. S5.0 architecture can utilize diverse technologically innovative solutions to offer environmental security for citizens, and these technologies can be aligned across major partitions, particularly in the case of waste management (Mavrodieva \& Shaw, 2020). Local governments should collect and examine data and access big data to develop cyberspace architecture where humans, in alliance with machines, can plan conservation activities (Mohanty \& Kumar, 2021; Foresti et al., 2020). However, replacing aging infrastructure is expensive. In decreasing population scenarios, switching to a substructure appropriate for small-scale populations instead of preserving a whole infrastructure system is recommended.

The results show that technology is a critical aspect affecting the capability of SSWM practitioners to utilize advanced technology to reduce risk and improve management efficiency (Tsai et al., 2020c). This examination of SSWM highlights that the S5.0 vision needs to incorporate global trends, rapid changes driven by technology, and unparalleled increases in data (Fukuda, 2020). Although S5.0 integrates technological products/services into daily life, we should be aware of the rapid technological development and digitization necessary to enhance SSWM and realize the full potential of its operational mechanisms. Integrating SSWM into S5.0 is a difficult because of challenges related to technological adoption, disqualifying components of poor digital infrastructure, deficiencies in national strategies, specialized expertise, and knowledge and information sharing and distribution regarding complex individual and societal challenges such as insufficient funding, aging populations and natural disasters. It is ideal to strive for a supersmart society that leverages advanced digital technologies such as Al and Internet-of-Things applications to modernize SSWM, making it more data-driven, citizen-centric, and oriented towards cybersecurity, traceability, and citizen data and privacy. Creating new policy systems and implementing security, privacy, ethics, and stability mechanisms to protect human values and maintain sustainable growth are of utmost importance.

Social and technical perspectives should be prioritized in relation to efforts to improve SSWM performance. In S5.0, prosperity and information are decentralized and distributed throughout society, and SSWM systems must align well with sociotechnical challenges to support a sustainable environment. On the one hand, technical perspective is embedded into every aspect of society to support community well-being, handle social problems and increase productivity. This frees people from high environmental constraints related to regional diversity and mass resource consumption through advanced waste management and allows them to live in harmony with nature. However, importantly, society empathy and real human interactions cannot be altered by technology such as Al or robotics. These system designs continuously face contradictory requirements and situations introduced by structural social schemes composed of different elements. The solid waste problems of society have immensely intensified due to industrial and manufacturing innovation, and this must be addressed with diverse waste generation approaches and management techniques, as humans decide what kind of waste they produce and how much waste they generate. Cultural contexts imperatively influence the human-robot communication, and the acquiescence of these technologies must become a priority in creating a new societal paradigm. Therefore, to integrate SSWM into S5.0, sociocultural issues must be incorporated with environmental issues to enable improved fiscal 
performance. Strong societal, political, and economic measures are needed to overcome or at

765 least mitigate the challenges faced in fostering clear, affordable, and available SSWM.

7665.2. Practical implications

767 The utmost important barriers to SSWM are acknowledged as (1) diverse groups and sectors

768 in local, national, and global communities, (2) a lack of mobility and reliability, (3) mass

769 production and mass consumption, (4) insufficient Al application, and (5) failures related to data

770 management and security; these are the most concerning barriers that decision makers need to

771 address to improve SSWM and achieve S5.0 in practice.

772 SSWM barriers in local, national, and global communities require much research-based

773 analysis regarding S5.0 and its applicability because of academic knowledge and global awareness

774 deficiency, as well as a certain level of uncertainty, on the topic. Although global organizations

775 have established SSWM norms and standards for governments and corporations at the national

776 level, governments have not made enough progress in this field due to operational failures in

777 terms of their structural and economic reform plans. Specifically, national-level governments can

778 act to reduce solid waste pollution through medium- or long-term development plans based on

779 their current situations and possible future trends. It could issue regulations and ordinances

780 restricting the use of products with high emissions, assessing the implementation of waste

781 treatment systems, and establishing safe, sustainable transportation and smart technical

782 standards for society. Actions that can be partially implemented at the local level are likely to

783 have immediate or short-term impacts. Ordinances related to solid waste can be applied at the

784 local level, but since production and trade do not just occur within local community boundaries,

785 the enforcement of such SSWM ordinances will be difficult, as they affect various cultures'

786 perspectives on solid waste generated and treatment by households, tourism, businesses,

787 industries, institutions, and individuals inside and outside communities. There is a need to

788 provide responsible officials at the local level with complete S5.0 planning procedures and

789 appropriate monitoring systems. Furthermore, behavioral changes and appropriate

790 programming and tools for technical assistance are required to address different community

791 groups through awareness programs. This is to avoid or minimize increases in costs and other

792 unsustainable results.

793 Mobility and reliability factors ensure environmental protection, an optimal recycling rate, 794 low carbon emissions, and green growth while meeting the conditions needed to implement 795 SSWM in S5.0 perspective; some problems related to this issue include public costs, a lack of 796 awareness, insufficient databases, and the increasing comprehensive socialization of activities in 797 the field of quality management. To make SSWM more reliable, different methods of service 798 payment and waste collection need to be implemented. Both businesses and employees should 799 be required to take part in the system, and the support of households or cities must be given to 800 counter their response to community-based services. Indeed, mobility and reliability can cause 801 polluters and communities to take actions that benefit environment users. Applying economic 802 tools in the context of environmental management is advised to limit environmental pollution 803 and degradation. However, for an SSWM practitioner, it is advisable to rigidly and strictly follow 804 regulation. In the long run, authorities are encouraged to comply with the principles defined from 805 the beginning. This is both respecting these goals and creating a reputation with the community.

806 In Societies 3.0 and 4.0, human beings rely on activities that involve high environmental 807 impacts and massive resource consumption. This contributes to climate change, and mass 
production and mass consumption create waste that impacts biodiversity; such production and consumption is often dependent on exploitive, impractical and even illegal conditions. Taiwan, which is poor in natural resources and faces ongoing resource depletion, should certainly leave the current societal system to ensure efficient use of its resources. S5.0 perspective exploits information to increase energy decentralization and efficiency, will help SSWM become off-grid and independent of outdated energy systems. SSWM will develop in terms of both systemic and technological requirements, thus allowing people to adopt sustainable lifestyles. Additionally, investment in the field of human resources, with an emphasis on the importance of active learning, is necessary to make a difference in solving mass production problems. Data on materials or substances produced with natural resources and recycled waste can be used as inputs to human production and consumption activities. Cities can provide waste transfer apparatuses and ward budgets that can be used for communication with community assistance organizations and to help spread information about the SSWM attribute, raising awareness not only among citizens but also among other populous communities.

$\mathrm{Al}$ is a replication of human intelligence in machines that simulate programmed to humans cogitate and imitate their activities, such as learning and problem solving. Big data and Al can be used to solve SSWM problems in S5.0. Al and robots can be utilized to build and maintain transportation networks and waste management infrastructure, replacing humans to limit their expose to hazardous waste and infection. Extending the use of Al and information sharing between humans and robots is needed, but humans generally want to have the right of control. Therefore, collaborative control is an important consideration for SSWM in optimal intelligent societies. Thus, unexpected accidents can be avoided and safety and reliability can be increased. However, so far, Taiwan has not had a government policy on critical Al technology. Such technologies carry potential risks, such as cyber-attacks, data privacy concerns, accountability issues, increased maintenance and enhancement expenses, and amplified social inequality, which justify consideration. The insufficiency of Al and the Social 5.0 methodology emphasize the need for physical network convergence, and the traditional approach must be changed to build a better community. Yet, extreme robotization, productivity improvements and increased automation impact job demand and lead to even more business losses, which have a net impact on employment. This study emphasizes the importance of true human interactions, and sympathetic Al cannot replace the role of humans in SSWM. Therefore, for employees, the "Internet of Abilities" should be used to enhance synergistic interconnections between humans and $\mathrm{Al}$, where people can discover and improve their own abilities using Al capabilities.

Data management and security, at least for the foreseeable future; however, this progress also presents unique ethical, legal, social, privacy, security, and safety challenges that need to be addressed before actual changes are made. Particularly, the S5.0 baseline should be a broad contextual platform used to generate expertise and pioneer SSWM, which is a vital part of all municipalities. The responsibility for data collection and management should rest with SSWM staff and organizations and should be in line with corporate requirements regarding the addition of digital social investigation value. In Taiwan, the absence of knowledge and progress needs to be highlighted, as the country's waste management data are either incomplete or aggregated and its communications tend to be unstable. It is difficult to organize citizen data, especially at the municipal level and within small waste management agencies. Moreover, the public required to be aware of who handles their data, monitors it, and in what way it is gathered, disposed of 


\section{Conclusion}

and distributed. Trust is a key element of technology acceptance. Open information and privacy approaches are increasingly important strategies for encouraging citizen involvement and intensifying trust via greater transparency and traceability. It is urgent to generate trust in the aforementioned technology, and in the authorities and SSWM organizations that control them, while ensuring cybersecurity protection.

Sustainable development goals under S5.0 empower the creation of a new biosphere in which human beings lead wealthy and gratifying lives in harmony with social, economic, and technological progress that occurs without harming nature. SSWM, as a critical, integral part of society, has long-term effects on the environment and human life and has become a particularly important consideration in the context of S5.0. However, making any tangible achievement in this regard is difficult due to a lack of local government capability and the current technical and economic conditions. The difficulties faced in creating systematized processes form many barriers and challenges that keep unsustainable waste management practices in place. This study evaluates TBL perspectives of sustainability in addition to technical challenges in the context of SSWM within S5.0; 45 barriers based on 8 aspects of an initial set of attributes are proposed. A hybrid method including the FDM, the fuzzy DEMATEL method and a Choquet integral is adopted to develop valid hierarchical measures and a causal interrelationship structure among these barriers, as well as to identify critical barriers to Taiwan's SSWM practices.

Twenty barriers belonging to 7 aspects are accepted and added to a valid SSWM hierarchical structure for S5.0. The results show that community uncertainty, policy and regulation problems, city architecture, and technology interaction are aspects that significantly influence SSWM in S5.0. The most important barriers are identified as diverse disciplines and sectors in local, national, and global communities; a lack of mobility and reliability; mass production and mass consumption; insufficient Al application; and failures related to data management and security. These are the most important barriers that decision makers need to address to improve SSWM and achieve S5.0 in practice. Social and technical perspectives are identified as top priorities for improved SSWM performance.

This study makes both theoretical and practical contributions. A valid and reliable set of SSWM barriers rooted in S5.0 is presented to extend the current understanding of both SSWM and S5.0 in the literature; SSWM-related causal interrelationships are examined within the proposed hierarchical structure, and the interdependent factors among the proposed barriers are identified. Since S5.0 is primarily relied on advanced technologies, the social acceptance of technology and the synchronization of political and regulatory objectives in the context of SSWM social-technical innovations are needed to improve waste management reliability and mobility and prevent legally binding risk. Critical barriers are identified for the practical improvement and enhancement of SSWM performance in the context of S5.0. Overcoming problems related to diverse groups and sectors in local, national, and global communities; a lack of mobility and reliability; mass production and mass consumption; insufficient Al application; and failures related to data management and security can help SSWM practitioners minimize operational uncertainty. S5.0 exhibits immensely intensified solid waste problems stemming from industrial and manufacturing innovations, which are used to assist professionals and decision-makers in obtaining a better vision and strategies. 
This study holds some limitations. First, the examined barriers are acquired from the literature, and the use of experts' evaluations causes hierarchical structures to be limited in nature; additionally, S5.0 perspective is only supported by a few literatures. Future studies can deepen this one by integrating more practical elements into the structure or focusing on only specific barriers to challenges. Second, a hybrid multicriteria decision-making method is adopted to evaluate the examined attributes; the participating experts' understanding and experience may lead to subjective judgments that impact the results. Therefore, a larger sample size may help future studies solve this bias problem. Third, this study focuses only on SSWM in Taiwan; thus, its generalizability is limited. Future studies can extend this investigation to other cities or countries, especially developing countries or areas with minimal or incomplete SSWM systems, examining the differences between them and hence enriching the literature.

\section{Author Contributions}

Ming-Lang Tseng- Conceptualize, original version and finalized the final version; and Tat-Dat Bui Conceptualize, original version and finalized the final version.

\section{Availability of data and materials}

No authorized

\section{Consent to Participate}

Not applicable

\section{Consent to Publish}

Not applicable

\section{Competing Interests}

Not applicable

\section{Ethical Approval}

Not applicable

\section{Funding Declaration}

This study is partially supported from MOST 110-2222-E-468-002-, Ministry of Science and Technology, Taiwan

\section{References}

Ahsan, A., Alamgir, M., El-Sergany, M. M., Shams, S., Rowshon, M. K., \& Daud, N. N. (2014). Assessment of municipal solid waste management system in a developing country. Chinese Journal of Engineering, 2014(12a), 1-11.

Aid, G., Eklund, M., Anderberg, S., \& Baas, L. (2017). Expanding roles for the Swedish waste management sector in inter-organizational resource management. Resources, Conservation and Recycling, 124, 85-97.

Anagnostopoulos, T., Zaslavsky, A., Kolomvatsos, K., Medvedev, A., Amirian, P., Morley, J., \& Hadjieftymiades, S. (2017). Challenges and opportunities of waste management in loT- 
enabled smart cities: A survey. IEEE Transactions on Sustainable Computing, 2(3), 275-289. Bryndin, E. (2018). System synergetic formation of society 5.0 for development of vital spaces on basis of ecological economic and social programs. Annals of Ecology and Environmental Science, 2(4), 12-19.

Bui, T. D., Tsai, F. M., Tseng, M. L., \& Ali, M. H. (2020a). Identifying sustainable solid waste management barriers in practice using the fuzzy Delphi method. Resources, conservation and recycling, 154, 104625.

Bui, T. D., Tsai, F. M., Tseng, M. L., Wu, K. J., \& Chiu, A. S. (2020b). Effective municipal solid waste management capability under uncertainty in Vietnam: utilizing economic efficiency and technology to foster social mobilization and environmental integrity. Journal of Cleaner Production, 259, 120981.

Casazza, M., \& Gioppo, L. (2020). A playwriting technique to engage on a shared reflective enquiry about the social sustainability of robotization and artificial intelligence. Journal of Cleaner Production, 248, 119201.

Dubey, S., Singh, P., Yadav, P., \& Singh, K. K. (2020). Household Waste Management System Using IoT and Machine Learning. Procedia Computer Science, 167, 1950-1959.

Environmental Protection Administration. Executive Yuan. 2020. Regulation for Recycling, Clearance and Disposal of General Wastes. Available online: https://law.moj.gov.tw/LawClass/LawAll.aspx?pcode=00050024 (accessed on 1 March, 2021).

Environmental Protection Administration. Executive Yuan. 2021. Taiwan Keeps Striving to Reduce Carbon Despite Rankings by Global Performance Index. Available online: https://www.epa.gov.tw/eng/F7AB26007B8FE8DF/04820b7c-f312-4a80-bced398ba51a2b39 (accessed on 1 March, 2021).

Ferreira, C. M., \& Serpa, S. (2018). Society 5.0 and social development. Management and Organizational Studies ,(5), 26-31.

Foresti, R., Rossi, S., Magnani, M., Bianco, C. G. L., \& Delmonte, N. (2020). Smart society and artificial intelligence: big data scheduling and the global standard method applied to smart maintenance. Engineering, 6(7), 835-846.

Fukuda, K. (2020). Science, technology and innovation ecosystem transformation toward society 5.0. International Journal of Production Economics, 220, 107460.

Fukuyama, M. (2018). Society 5.0: Aiming for a new human-centered society. Japan Spotlight, 27, 47-50.

Gladden, M. E. (2019). Who will be the members of Society 5.0? Towards an anthropology of technologically posthumanized future societies. Social Sciences, 8(5), 148.

Gonzalez, E. D., Sarkis, J., Huisingh, D., Huatuco, L. H., Maculan, N., Montoya-Torres, J. R., \& de Almeida, C. M. (2015). Making real progress toward more sustainable societies using decision support models and tools: introduction to the special volume.Journal of Cleaner Production, 105, 1-13.

Grabisch, M. (1996). The application of fuzzy integrals in multicriteria decision making. European Journal of Operational Research. 89 (3): 445-456

Gutberlet, J., Carenzo, S., Kain, J. H., \& Mantovani Martiniano de Azevedo, A. (2017). Waste picker organizations and their contribution to the circular economy: Two case studies from a global south perspective. Resources, 6(4), 52. 
Huber-Humer, M., \& Lechner, P. (2011). Sustainable landfilling or sustainable society without landfilling?. Waste management, 7(31), 1427-1428.

Ikhlayel, M. (2018). Indicators for establishing and assessing waste management systems in developing countries: a holistic approach to sustainability and business opportunities. Business Strategy \& Development, 1(1), 31-42.

Ishikawa, A., Amagasa, M., Shiga, T., Tomizawa, G., Tatsuta, R., \& Mieno, H. (1993). The max-min Delphi method and fuzzy Delphi method via fuzzy integration. Fuzzy Sets and Systems, 55(3), 241-253.

Islam, K. N., \& Jashimuddin, M. (2017). Reliability and economic analysis of moving towards wastes to energy recovery based waste less sustainable society in Bangladesh: The case of commercial capital city Chittagong. Sustainable Cities and Society, 29, 118-129.

Keogh, J. G., Dube, L., Rejeb, A., Hand, K. J., Khan, N., \& Dean, K. (2020). The Future Food Chain: Digitization as an Enabler of Society 5.0. Building the Future of Food Safety Technology; Detwiler, D., Ed.

Marino, A. L., Chaves, G. D. L. D., \& dos Santos Junior, J. L. (2018). Do Brazilian municipalities have the technical capacity to implement solid waste management at the local level?. Journal of Cleaner Production, 188, 378-386.

Mavrodieva, A. V., \& Shaw, R. (2020). Disaster and Climate Change Issues in Japan's Society 5.0A Discussion. Sustainability, 12(5), 1893.

Mohanty, R., \& Kumar, B. P. (2021). Urbanization and smart cities. In Solving Urban Infrastructure Problems Using Smart City Technologies (pp. 143-158). Elsevier.

Mohsenizadeh, M., Tural, M. K., \& Kentel, E. (2020). Municipal solid waste management with cost minimization and emission control objectives: A case study of Ankara. Sustainable Cities and Society, 52, 101807.

Murayama, A. (2020). Institutional instruments for urban systems designdfrom the planner's perspective. Urban Systems Design: Creating Sustainable Smart Cities in the Internet of Things Era, 409.

Ng, K. S., Yang, A., \& Yakovleva, N. (2019). Sustainable waste management through synergistic utilisation of commercial and domestic organic waste for efficient resource recovery and valorisation in the UK. Journal of Cleaner Production, 227, 248-262.

Nguyen, K. L. P., Chuang, Y. H., Chen, H. W., \& Chang, C. C. (2020). Impacts of socioeconomic changes on municipal solid waste characteristics in Taiwan. Resources, Conservation and Recycling, 161, 104931.

Onoda, H. (2020). Smart approaches to waste management for post-COVID-19 smart cities in Japan. IET Smart Cities, 2(2), 89-94.

Roblek, V., Meško, M., Bach, M. P., Thorpe, O., \& Šprajc, P. (2020). The Interaction between Internet, Sustainable Development, and Emergence of Society 5.0. Data, 5(3), 80.

Sakr, D., Baas, L., El-Haggar, S., \& Huisingh, D. (2011). Critical success and limiting factors for ecoindustrial parks: global trends and Egyptian context. Journal of Cleaner Production, 19(11), 1158-1169.

Sharma, M., Joshi, S., Kannan, D., Govindan, K., Singh, R., \& Purohit, H. C. (2020). Internet of Things (IoT) adoption barriers of smart cities' waste management: An Indian context. Journal of Cleaner Production, 122047.

Sung, H. C., Sheu, Y. S., Yang, B. Y., \& Ko, C. H. (2020). Municipal Solid Waste and Utility 
Consumption in Taiwan. Sustainability, 12(8), 3425.

Tabaa, M., Monteiro, F., Bensag, H., \& Dandache, A. (2020). Green Industrial Internet of Things from a smart industry perspectives. Energy Reports, 6, 430-446.

Tanaka, M. (2014). Sustainable society and municipal solid waste management. In Municipal Solid Waste Management in Asia and the Pacific Islands (pp. 1-14). Springer, Singapore.

Tsai, F. M., Bui, T. D., Tseng, M. L., \& Wu, K. J. (2020b). A causal municipal solid waste management model for sustainable cities in Vietnam under uncertainty: A comparison. Resources, Conservation and Recycling, 154, 104599.

Tsai, F. M., Bui, T. D., Tseng, M. L., Lim, M. K., Wu, K. J., \& Mashud, A. H. M. (2020a). Assessing a hierarchical sustainable solid waste management structure with qualitative information: Policy and regulations drive social impacts and stakeholder participation. Resources, Conservation and Recycling, 105285.

Tseng, M. L., Chiang, J. H., \& Lan, L. W. (2009). Selection of optimal supplier in supply chain management strategy with analytic network process and choquet integral. Computers \& Industrial Engineering, 57(1), 330-340.

Tseng, M. L., Lin, Y. H., Lim, M. K., \& Teehankee, B. L. (2015). Using a hybrid method to evaluate service innovation in the hotel industry. Applied Soft Computing, 28, 411-421.

Tseng, M. L., Wu, K. J., Lee, C. H., Lim, M. K., Bui, T. D., \& Chen, C. C. (2018). Assessing sustainable tourism in Vietnam: A hierarchical structure approach. Journal of cleaner production, 195, 406-417.

United Nations (2020). Transforming our world: The 2030 agenda for sustainable development. https://sustainabledevelopment.un.org/post2015/transformingourworld. (accessed on 1 March, 2021).

Yeh, L. T. (2020). Analysis of the dynamic electricity revenue inefficiencies of Taiwan's municipal solid waste incineration plants using data envelopment analysis. Waste Management, 107, 28-35.

Yukalang, N., Clarke, B., \& Ross, K. (2017). Barriers to effective municipal solid waste management in a rapidly urbanizing area in Thailand. International journal of environmental research and public health, 14(9), 1013. 
Figures

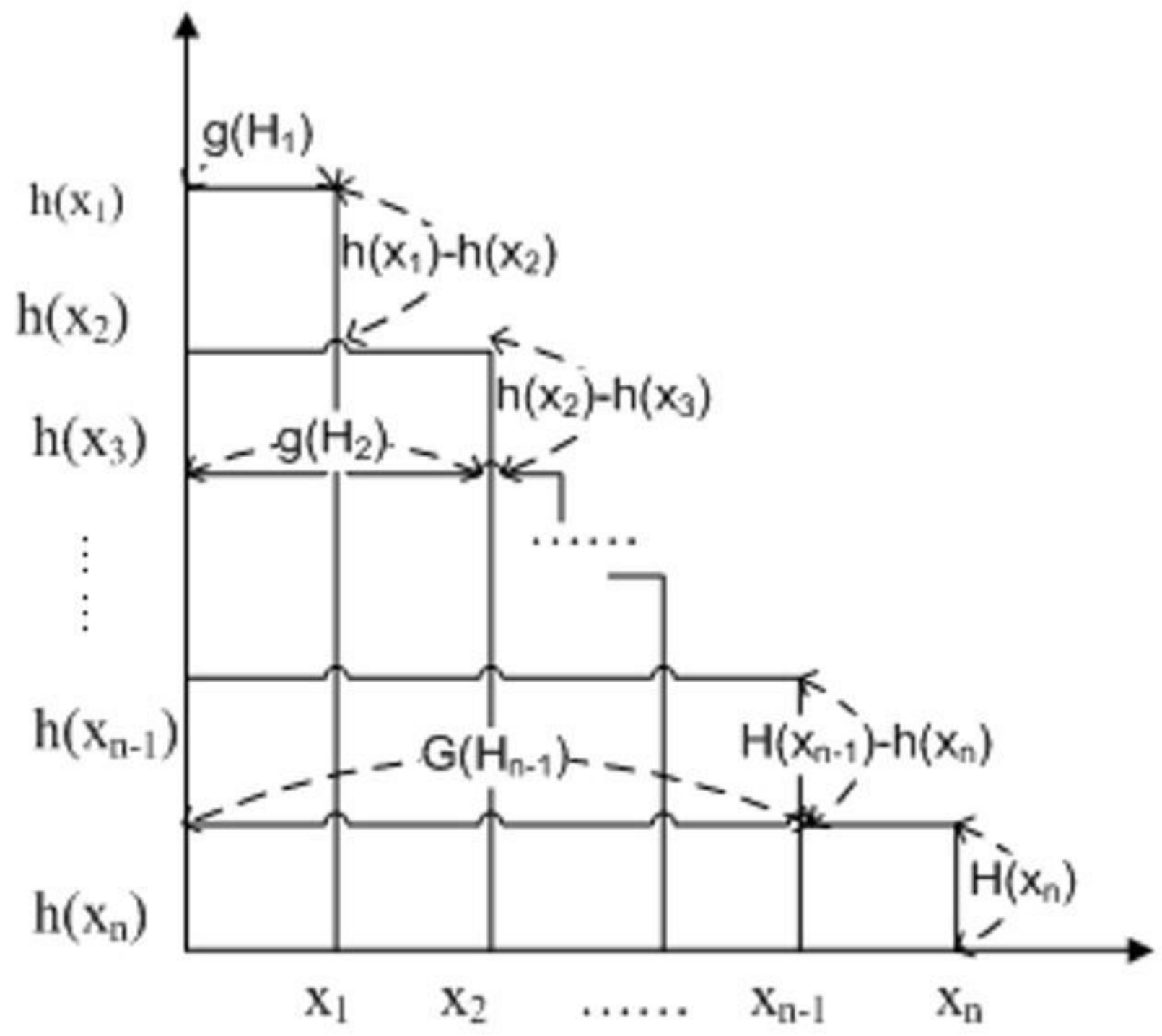

Figure 1

Choquet integral's basic concept 


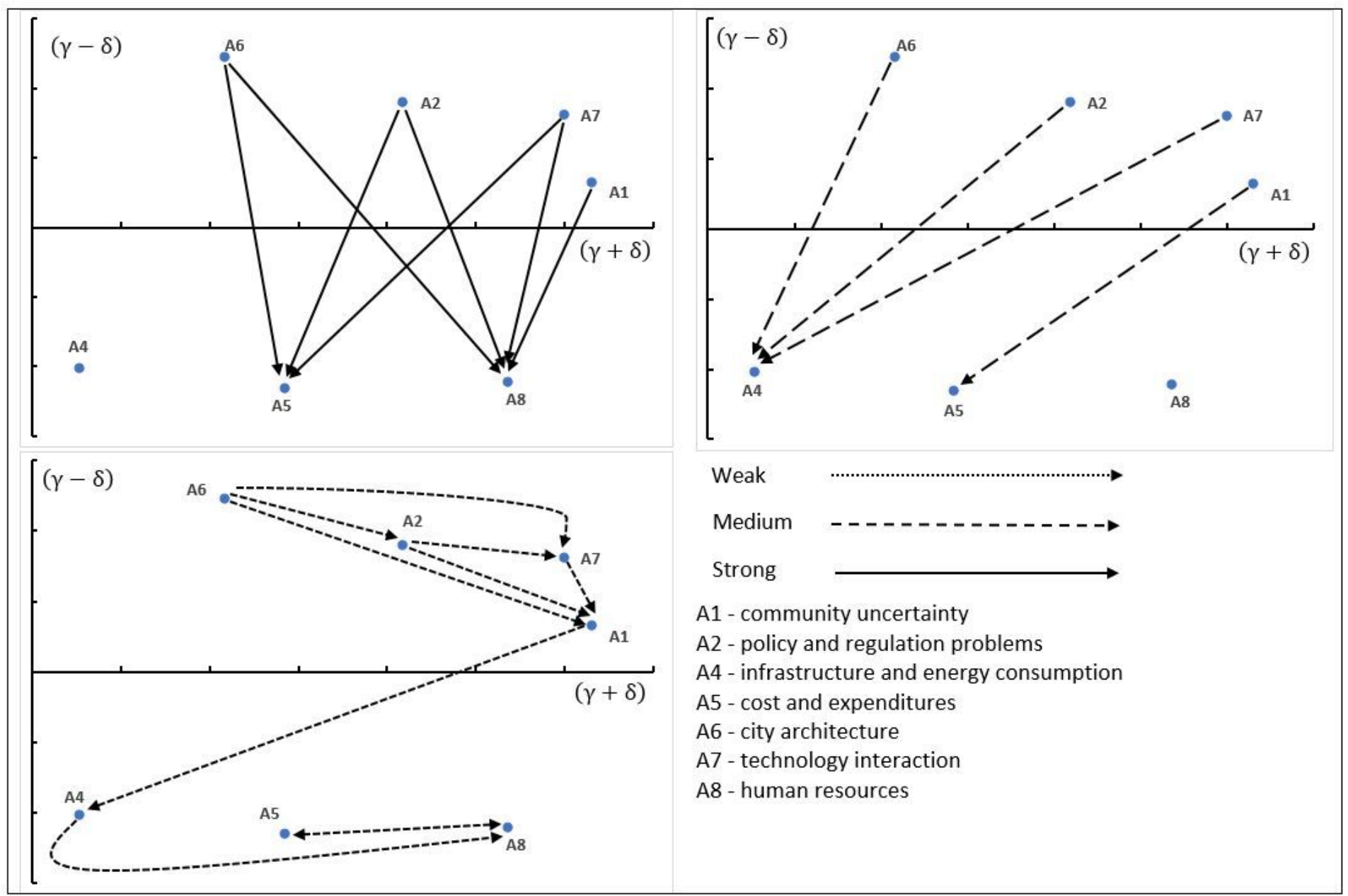

Figure 2

Aspect's cause-and-effect diagram 


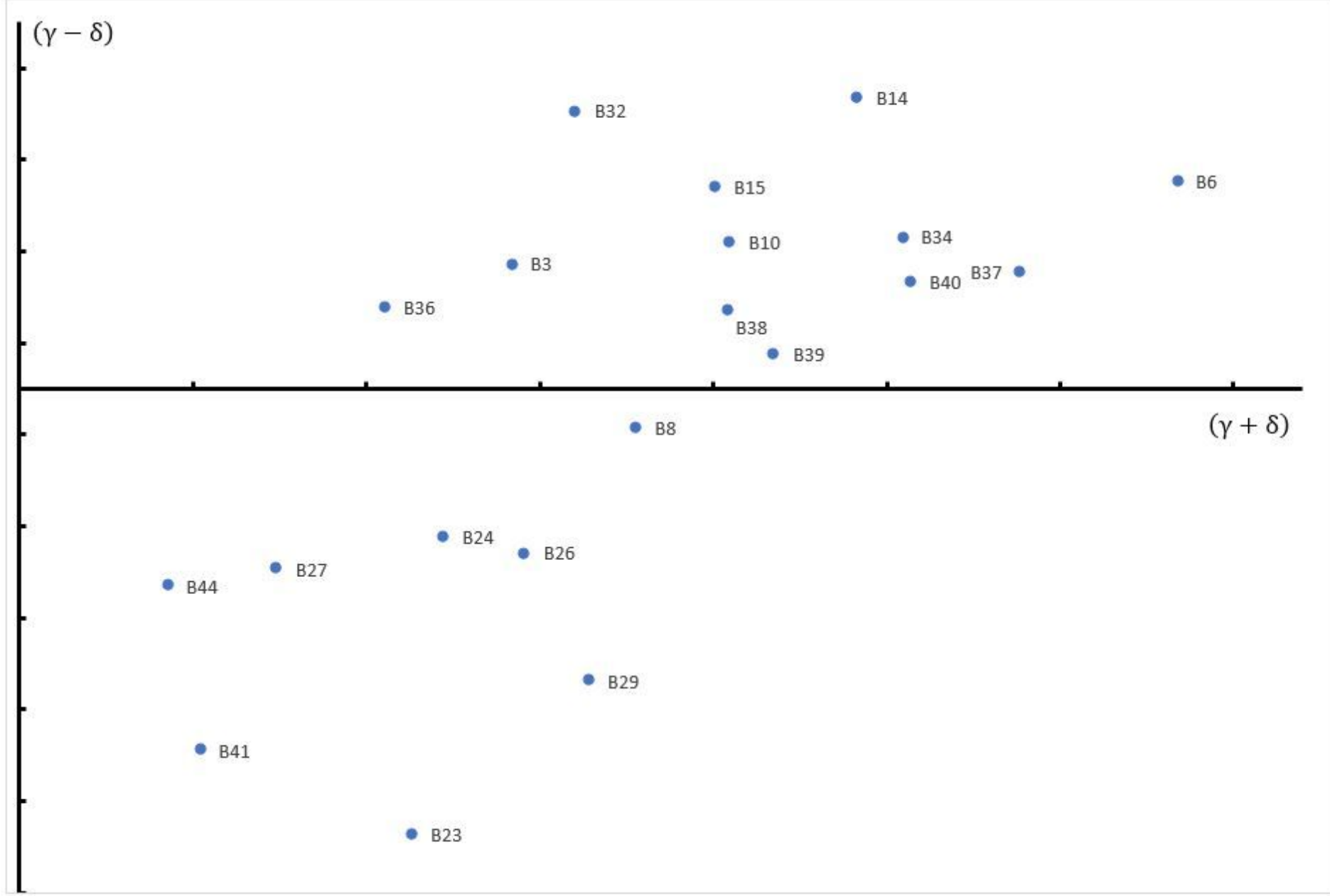

Figure 3

Criteria's causal diagram 


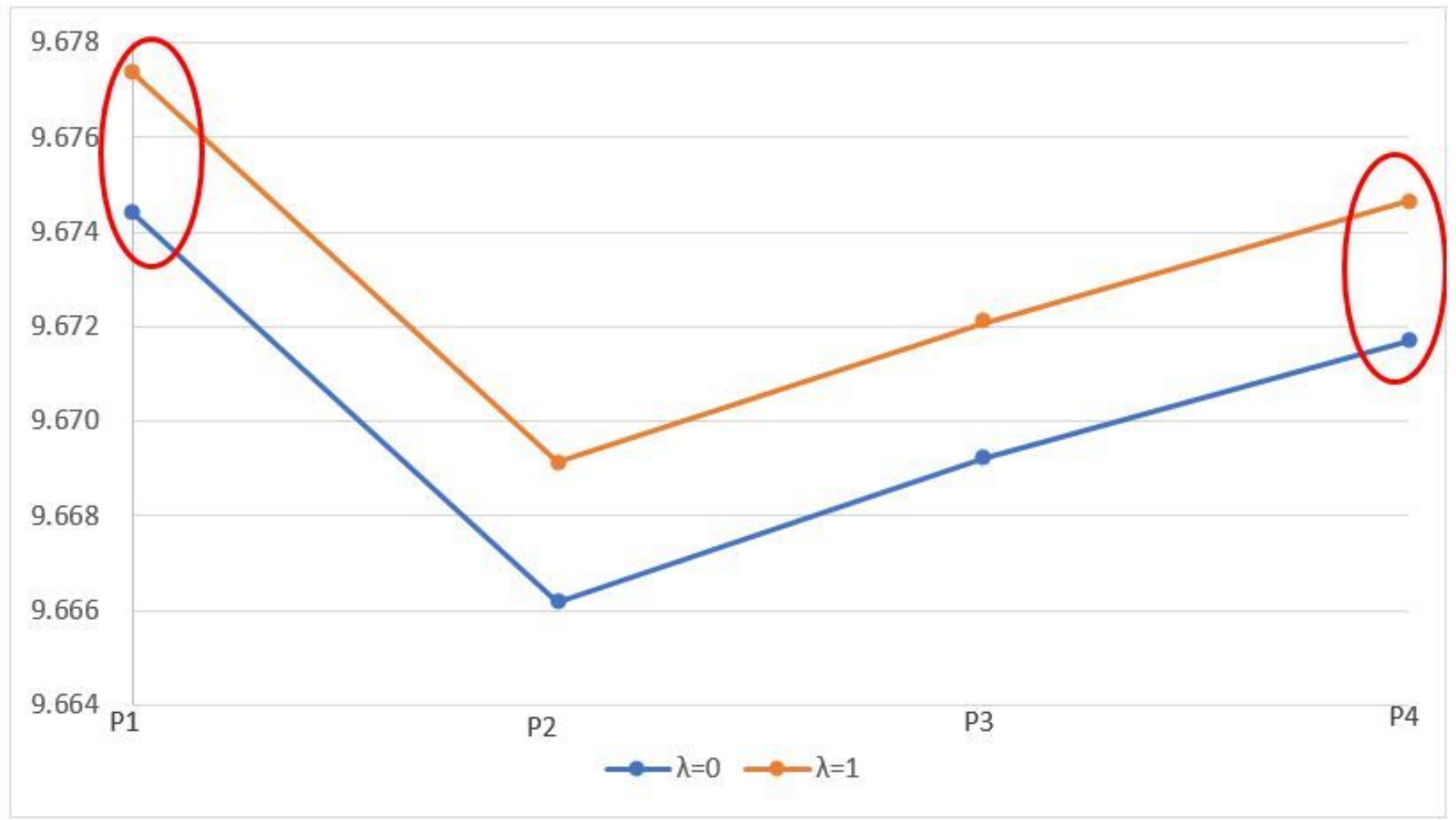

Figure 4

Choquet integral diagram

\section{Supplementary Files}

This is a list of supplementary files associated with this preprint. Click to download.

- Table10.jpg 